\title{
LLNL-TR-640474
}

LAWRENCE LIVERMORE NATIONAL LABORATORY

\section{Radiological Dispersal Device} Shelter \& Evacuation Technical Basis; CalEMA RNER Framework Supplement

\author{
B. R. Buddemeier \\ A.R. Wood-Zika
}

\section{June 2013}

This work was performed under the auspices of the U.S. Department of Energy by Lawrence Livermore National Laboratory under Contract DE-AC52-07NA27344.

This document was prepared as an account of work sponsored by an agency of the United States government. Neither the United States government nor Lawrence Livermore National Security, LLC, nor any of their employees makes any warranty, expressed or implied, or assumes any legal liability or responsibility for the accuracy, completeness, or usefulness of any information, apparatus, product, or process disclosed, or represents that its use would not infringe privately owned rights. Reference herein to any specific commercial product, process, or service by trade name, trademark, manufacturer, or otherwise does not necessarily constitute or imply its endorsement, recommendation, or favoring by the United States government or Lawrence Livermore National Security, LLC. The views and opinions of authors expressed herein do not necessarily state or reflect those of the United States government or Lawrence Livermore National Security, LLC, and shall not be used for advertising or product endorsement purposes. 


\section{Radiologica Dispersal Device}

\section{Shetter \& Evacuation Technical Basis CalEMA RNDR Eramework Supplement}

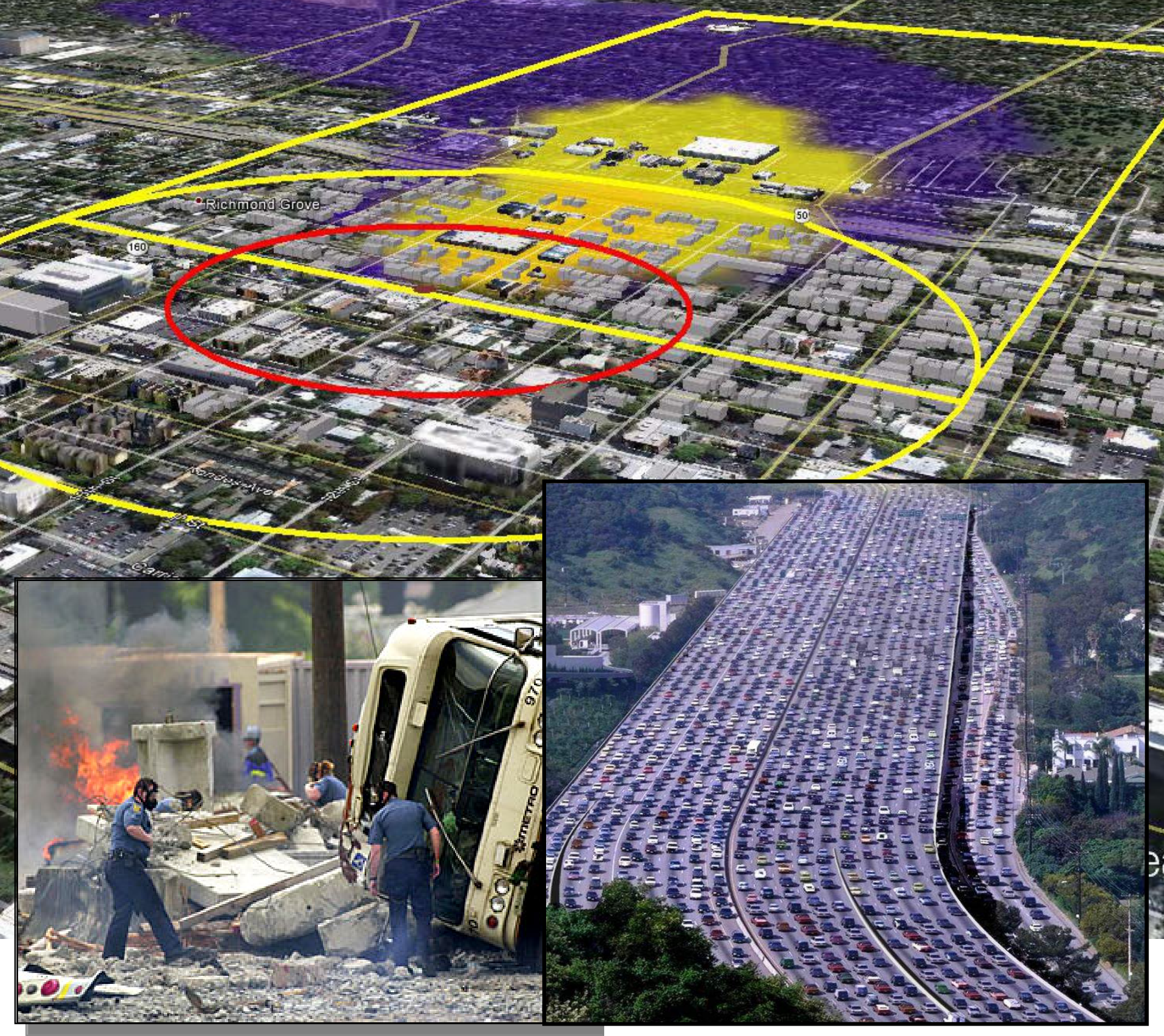




\section{RDD Shelter/Evacuation Technical Basis}

\section{Contents}

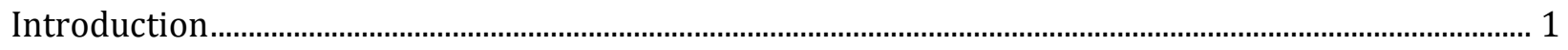

Assumptions and Constraints........................................................................................................................ 3

Initial Shelter \& Evacuation Guidance .............................................................................................................. 5

RDD Strategy Following an outdoor RDD or Dirty Bomb:............................................................................ 5

Immediate Shelter in Place followed by a delayed, deliberate evacuation of sheltered populations

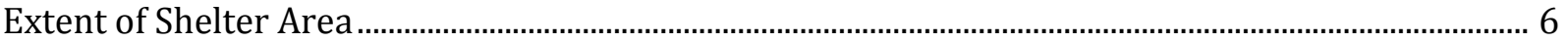

General Shelter \& Evacuation Bases and Considerations .................................................................................... 7

Weather Monitoring and Plume Modeling...................................................................................................... 7

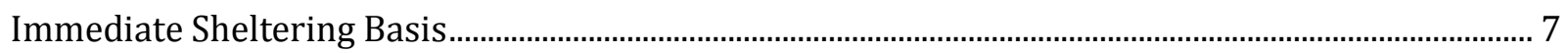

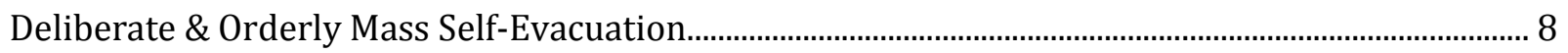

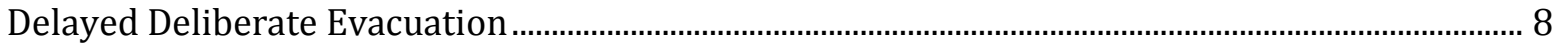

Evacuation Route Considerations ...................................................................................................... 8

Hazard Assessment and Control...................................................................................................................... 9

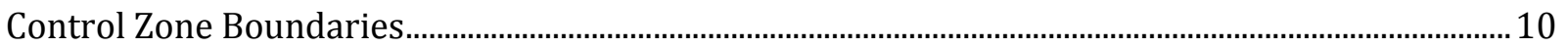

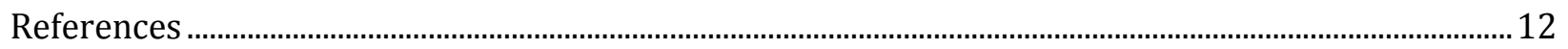

Appendix 1. RDD Response Summary Flow Chart ......................................................................................... 13

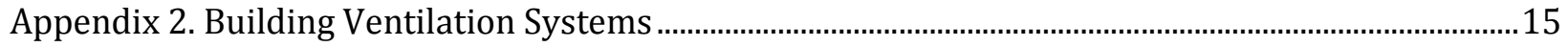

Appendix 3. Shelter/Evacuation and Control Zone Recommendation Reference Summary................18

Appendix 4: Additional Shelter/Evacuation References...............................................................................20 


\section{Introduction}

The Federal Protection Action Guidance ${ }^{1}$ makes the following recommendation for sheltering or evacuation for a radiological event:

\begin{tabular}{l|l|l|} 
Phase & Protective Action Recommendation & $\begin{array}{l}\text { Protective Action Guide or Planning } \\
\text { Guide }\end{array}$ \\
\hline Early & $\begin{array}{l}\text { Sheltering-in-place or evacuation of the } \\
\text { publica }\end{array}$ & $\begin{array}{l}1 \text { to } 5 \mathrm{rem}(10 \mathrm{mSv} \text { to } 50 \mathrm{mSv}) \text { projected } \\
\text { dose } / 4 \text { days }\end{array}$
\end{tabular}

(a) Should begin at 1 rem (10 mSv); take whichever action (or combination of actions) that results in the lowest exposure for the majority of the population. Sheltering may begin at lower levels if advantageous.

(b) Projected dose- the sum of the effective dose from external radiation exposure (i.e., groundshine and cloudshine) and the committed effective dose from inhaled radioactive material.

"Shelter-in-place" or "evacuation" are very different recommendations and can result in significantly different levels of exposure. Unfortunately, the action that provides the lowest exposure is not always apparent at the time and should be determined in advance to avoid potential confusion. A Shelter-in-Place strategy provides the best protection for the public after an outdoor Radiological Dispersal Device (RDD) or "dirty bomb." This document will review the technical basis for this strategy, and identify alternate strategies and when they should be considered.

The potential for radiological terrorism presents many challenges to first responder communities in terms of pre-planning, response actions, and post-event management. Key among these challenges is identifying appropriate initial response actions, including public protective actions such as shelter/evacuation decision-making, which spans the continuum of emergency and recovery phases.

Given the many uncertainties associated with the effects of an RDD event in an urban environment and the range of issues facing first responders in terms of threat identification, self-protection, and crowd control, it is not realistic to attempt to arrive at a set of specific recommendations for shelter/evacuation decision-making that would be applicable to all situations. This technical basis document presents sheltering and evacuation considerations and guidance and is meant to support development of multi-agency implementation procedures and decision-making tools.

There are long-standing federal recommendations regarding shelter/evaluation decision points, but no enforceable laws that help communities decide when shelter or evacuation is warranted. These decisions are most often based on a projected population dose that might occur if no action is taken. However, the corresponding operational information that would help the Incident Command determine if public exposure might exceed the level of concern or that will help the IC to prioritize radiological versus non-radiological risks is, in general, lacking in the early phase of the event.

\footnotetext{
${ }^{1}$ Environmental Protection Agency. (2013). Manual of Protective Action Guides and Protective Actions for Radiological Incidents. Draft for Interim Use and Public Comment. March 2013.
} 
This technical basis provides recommendations for initial response actions that specifically impact immediate protective actions/shelter and evacuation decision making, most specifically, immediate shelter/evacuation guidance to support population safety and establishment/control of radiological perimeters. The following general considerations and basis discussion are included:

- Weather monitoring and plume analysis

- Immediate sheltering basis

- Area zone/control definitions

- Hazard identification

- Evacuation route and crowd control considerations

The above considerations can be integrated with California operational strategies to provide consolidated initial RDD shelter and evacuation action recommendations. Supporting considerations and technical bases for this integrated approach are provided in subsequent sections and appendices to this document.

Throughout this document, references are made to the Los Angeles county Multi-Agency Radiological Response Plan (MARRP). Although this is not a statewide plan, it does provide useful definitions and concepts that can be applied elsewhere.

As with many plans, the MARRP provides guidance on how to define zones and actions once measurements are made (and with some default initial zones defined by range). The purpose of this document is to provide amplifying information for this guidance and other California response plans with initial recommendations based on the minimal information that would likely be available in the first few hours after a suspected RDD.

Currently, the MARRP uses 500m radius as an initial "exclusion zone." This document provides recommendations for updating the instructions for actions taken in that zone and the addition of a shelter-in-place downwind zone.

Ideally, emergency responders participating in the sheltering-versus-evacuation decision will utilize a "risk-based response" approach to arrive at an appropriate course of action. Risk-based response is a systematic process by which emergency responders analyze a problem involving hazardous materials - including radiological materials in the advent of a chemical, biological, or radiological (CBR) attack - to assess the hazards, evaluate the potential consequences, and determine appropriate response actions based upon facts and the circumstances on the incident. In this view, there are no absolute rules in emergency response, so the goal of this technical basis is not to attempt to set absolute actionable values as to when a particular course of action is warranted, but rather to supply the emergency response community with general guidance to reach informed decisions. 


\section{Assumptions and Constraints}

- The Urban environment will cause contamination to move in all directions around the release site, even "upwind." As shown in Figure 1, if the release occurs in an area where there is a significant number of large buildings, the material will "mix" in the immediate area in addition to being carried downwind.

- The initial high concentration of airborne (respirable) particulate will diminish rapidly. The large particles will settle on surfaces, and the small particles that can remain in the air (as smoke or haze) will tend to move downwind. The primary residual hazard will be direct radiation "shine" from surfaces and resuspension of deposited material into the air by human activity.

- Indoor exposures will be a small fraction compared to outdoor

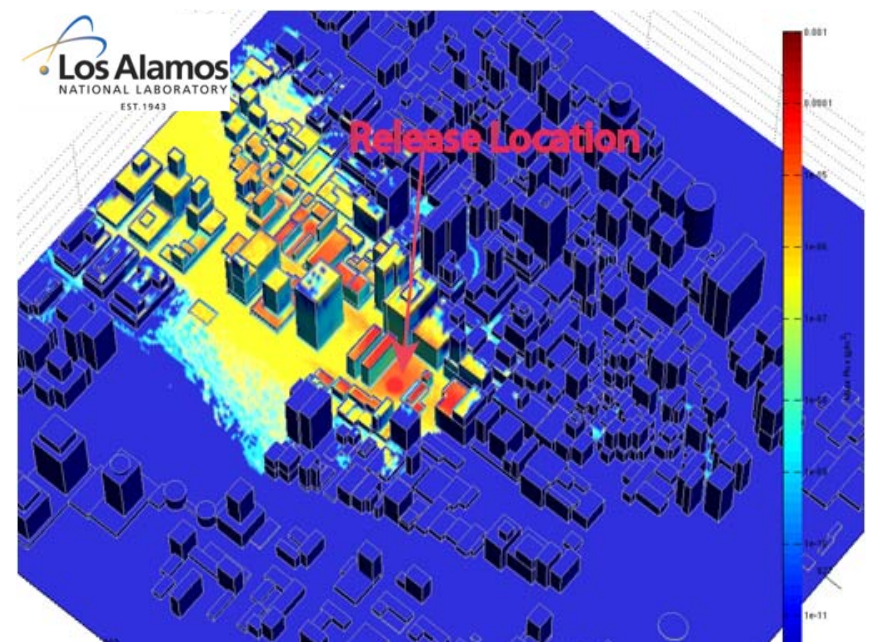

Figure 1. 3D view of contamination from an urban dirty bomb exposures. Figure 2 demonstrates

the indoor and outdoor exposures for a hypothetical scenario. Each color change represents a factor of 10 difference in exposure. As can be seen, the indoor exposure is often 100 times less than the outdoor exposure, even without any special building protective actions (such as sealing doors/windows and turning off HVAC). More on building protection and HVAC systems is in appendix 2

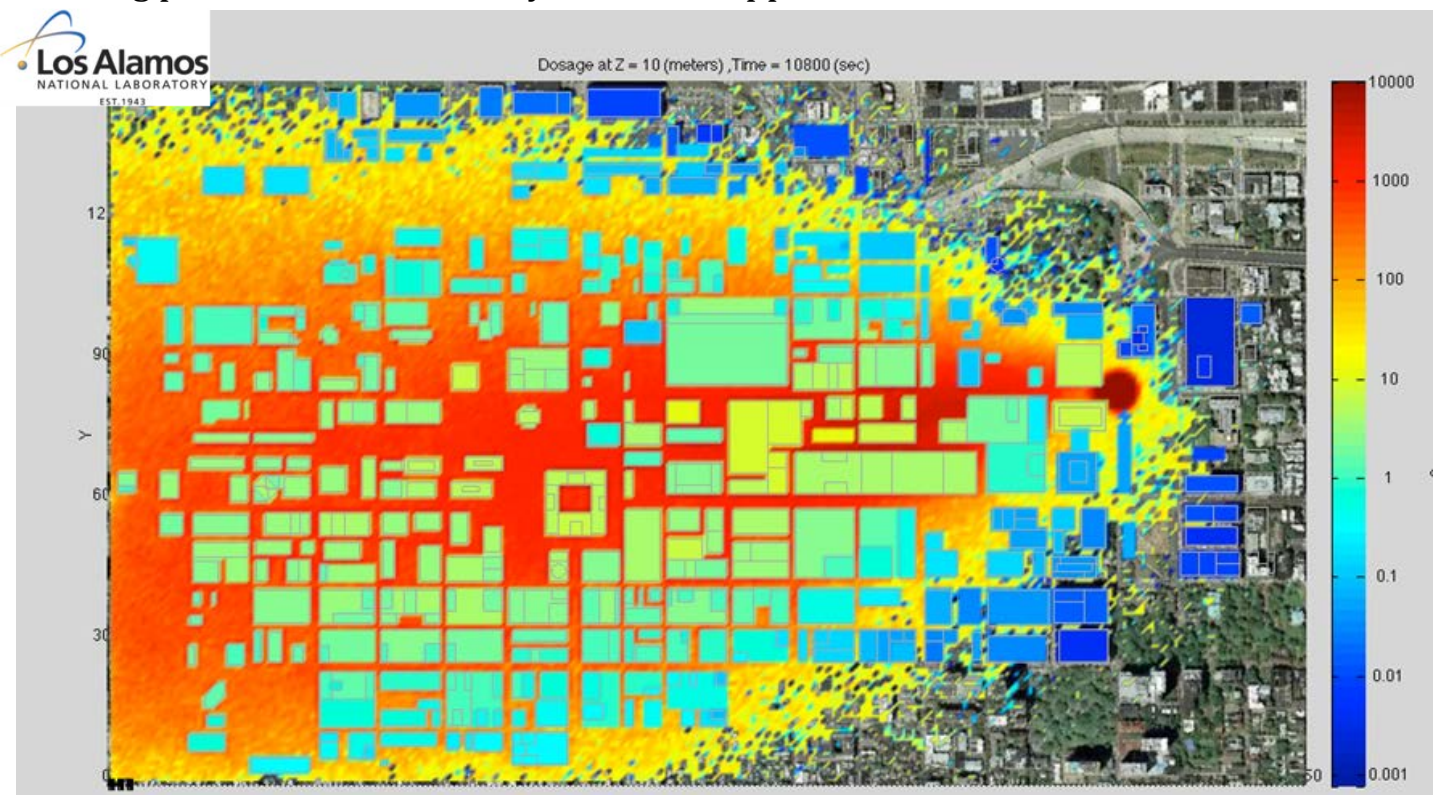

Figure 2. Interior and exterior exposures after an outdoor dirty bomb 
- Radiation may be detected quickly, but defining zones by contamination will take significantly longer. It is assumed that first Arriving Fire and Police Units on Scene will detect radiation. Radiation Detection capabilities are ubiquitous in Fire \& Police and generally operated in an "always on" mode during response.

- The Exclusion Zone, Shelter-in-Place area, and the area of detectable radiation are different in size. Figure 3 demonstrates the ranges of some potential areas that are used in the MARRP for (1) responder protective measures, (2) public protective measures, and (3) potential areas of public concern. In addition to the zones identified below and in Table 3 of the MARRP (see page 11 of this document), the MARRP early RDD guidance is "Begin setting up radiation control zones. Until those zones are established, assume an isolation/evacuation zone of 1,650 feet (500 meters)." This technical basis demonstrates how additional information is available to suggest adding a $2 \mathrm{~km}$ downwind area related to Shelter-in-Place actions should also be considered.

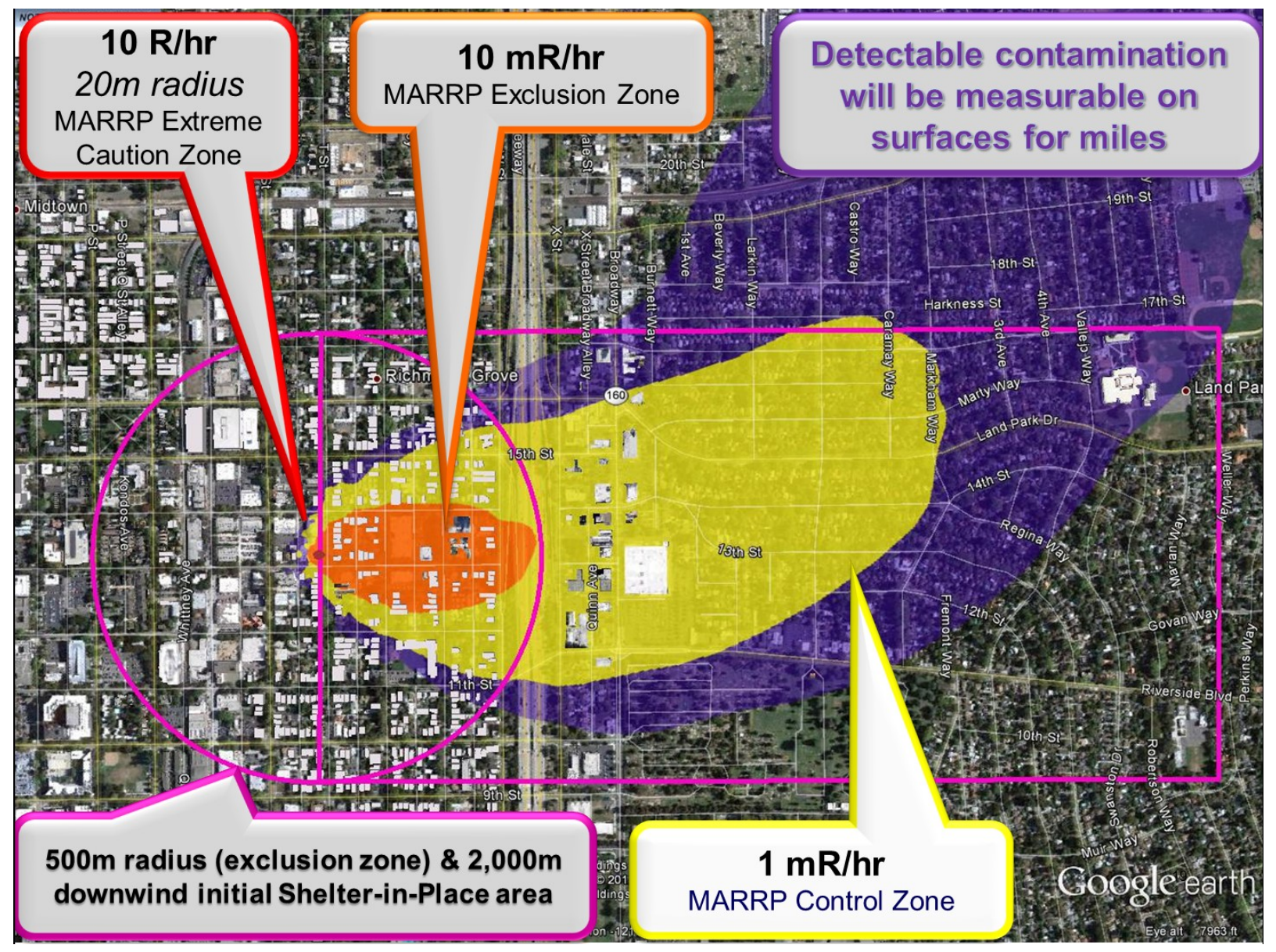

Figure 3. Ranges of various areas of concern. The Shelter area does not necessarily correspond to the Exclusion Zone.

- The onsite response force will be managing the incident, not extended area shelter efforts. Initial response efforts will focus on life safety issues at the site of the explosion, shelter-in-Place orders will be issued primarily by word of mouth to nearby members of the 
public. The $1 \mathrm{~km}$ wide, $2 \mathrm{~km}$ long Shelter-in-Place area may be beyond the ability of the local incident commander to manage.

- Local Leadership will manage extended area Shelter in Place efforts. The area in which shelter-in-Place is recommended is too large for local incident command and an EOC or Area Command should be used to coordinate activities.

This technical basis focuses on potential exposures, decision-making, and response actions that take place in the first few hours of the emergency (referred to as the Early Phase) of a radiological terrorism incident, specifically a large, sudden, outdoor release of radioactive material such as a "dirty bomb."

This document and its recommendations are not necessarily suited for response to other forms of radiological and nuclear terrorism response, such as a nuclear detonation, an indoor release of radioactive material, a radiological exposure device (without contamination), nuclear power plant accidents, or food borne contamination.

\section{Initial Shelter \& Evacuation Guidance}

For the purposes of this technical basis, initial response actions are defined as those operational activities undertaken at the outset of an $R D D$ event; it is important to recognize that the focus of these activities is on actions taken to avoid or reduce future radiation exposure to the public. There are two principal challenges associated with protective action planning and decision-making: (1) identifying protective actions that reduce (or eliminate) public exposure and (2) providing actionable information to responders on how to implement them.

\section{RDD Strategy Following an outdoor RDD or Dirty Bomb:}

\section{Immediate Shelter in Place followed by a delayed, deliberate evacuation of sheltered populations}

After an explosive release of radioactive material, the best way to avoid or reduce exposure for those that discover themselves in a potentially contaminated environment depends on location. The following (default) immediate shelter/evacuation guidance may be utilized, tailored to specific incident conditions:

1) If you are inside and your building is intact, stay inside.

2) If you are outside, or in a significantly damaged or "smoky" building,

a. move immediately in to the nearest robust, intact structure, and/or

b. move out of the area (if the event is small and there is a clear path out).

Why immediate (prompt) evacuation should be avoided:

- In the initial confusion of the event, evacuees may inadvertently evacuate into more heavily contaminated areas, 
- Immediate evacuation tends to be rushed, increasing breathing rates (and therefore internal exposure to airborne contaminates) and the possibility of accidents (either running or driving erratically), and

- It may be unwise to evacuate through an active emergency response area as this can be unsafe for members of the public and might complicate or interfere with emergency response efforts.

When immediate evacuation should be considered:

Evacuation can be effective if it can be accomplished before the explosion or radiological contamination arrives at the point of concern. For a no notice dispersal, this is generally not practical because:

- Those outdoors and in buildings near the event will not have time before the contaminants (smoke/particulate plume) reach them, and

- The radiological nature of the event may not be recognized until after responders arrive.

Situations when prompt or early evacuation is warranted:

- If the release occurred indoors (such as an office building, stadium, or subway) then that location should be immediately evacuated,

- If there is a continual release mechanism (such as a burning radioactive source or a sprayer device), then downwind areas should consider immediate evacuation as protection from the material that has yet to be aerosolized, and

- If there are non-radiological threats to life and limb at the shelter location such as fire, building collapse, or secondary explosive devices.

Delayed, deliberate evacuation means an orderly evacuation that occurs after the area has been sufficiently characterized to eliminate or minimize the extent of exposure during the building evacuation process. This would often occur several hours after the release when immediate life safety concerns have been managed.

\section{Extent of Shelter Area}

Work done by Lawrence Livermore National Laboratory, Sandia National Laboratories, and Brookhaven National Laboratory has helped inform the initial Exclusion Zone determination. The 2013 article, "Updated Emergency Response Guidance for the First $48 \mathrm{H}$ After the Outdoor Detonation of an Explosive Radiological Dispersal Device" (Musolino, 2013) demonstrates how the Exclusion Zone can be defined early in the event before the radiological extent is fully characterized.

As discussed in the paper, the area of Shelter-In-place is often larger than the MARRP Exclusion Zone. Consider an initial Shelter-in-Place area of:

- $500 \mathrm{~m}$ in all directions from the incident site

- $2,000 \mathrm{~m}$ (1.2 miles) downwind of the incident site. 
RDD Shelter/Evacuation Technical Basis

\section{General Shelter \& Evacuation Bases and Considerations}

Technical analysis of urban exposure pathways is a recognized useful tool for informing shelter/evacuation decision-making; however, a range of other considerations beyond modeled radiation doses must also be evaluated, including psycho-social factors, building integrity, ready access to potential evacuation routes, and the possibility of secondary events.

\section{Weather Monitoring and Plume Modeling}

An explosive RDD will generate radioactive particles of a variety of sizes that will be transported in various ways and expose the population to radiation through several dose pathways (e.g., inhalation, external exposure from groundshine and cloud submersion, etc ). It is recognized that computer modeling can be a useful tool for analyzing radioactive particle dispersion in an urban environment and informing shelter versus evacuation decision-making. Computer models can be used to examine results for reasonable and worst-case RDD scenarios (i.e., to bound the problem), to explore various meteorological and source term conditions, and to address specific issues (such as building protection, urban morphology, terrain or city types, etc.) that might raise or lower the overall outcome of an RDD event, assuming that the information can be synthesized in advance to produce general guidelines - modeled radiation doses following an event will almost certainly not be available in time for first responders to depend on for initial evacuation/sheltering decisions.

\section{Immediate Sheltering Basis}

A variety of radiological incident shelter/evacuation guidance documents have been issued over the past decades, as summarized in Appendix 4. In general, NCRP 165 recommendations are adopted for this technical basis, with additional input from CDC, FEMA, CRCPD, and RadCPR resources.

NCRP 165 recommended immediate sheltering followed by delayed, informed evacuation. People indoors should remain indoors until the plume of airborne radioactive material has passed. Informing members of the general public of this protective action before an incident occurs will reduce exposure.

Existing federal guidance and modeling analyses suggest a significant protective effect from remaining inside buildings immediately after an RDD event. For outdoor explosions, most of the airborne radioactive dust will have settled to the ground within about 10 minutes (Ref. Harper / Musolino). In the absence of any other information, Harper/Musolino recommend evacuation of anyone in the open environment to 500 meters $(1650 \mathrm{ft}$ ) from the detonation site in all directions. For people in intact buildings in the immediate surroundings of the event, sheltering in the early phase of response is the preferred course of action being recommended by federal agencies and professional organizations (additional considerations and bases are included in Appendix 3). If a building is structurally compromised, occupants should evacuate immediately and attempt to move away from the detonation site to a safe location to receive medical attention or await further instructions from emergency responders. If at any time the indoor radiation levels exceed outdoor radiation levels, immediately evacuate. Although it is unlikely that significant exposures will occur at greater distances, longer distances downwind should be included in the protective recommendations. 
RDD Shelter/Evacuation Technical Basis

\section{Deliberate \& Orderly Mass Self-Evacuation}

Based on the actual experience after the attacks on the World Trade Center, the plan for managing evacuees should presume an orderly mass self-evacuation. With that assumption, having advance community planning efforts in place that direct self-evacuees to avoid crossing the Exclusion Zone are important. At the appropriate time initial emergency responders should be prepared to guide evacuees along designated evacuation routes which have established egress locations far away from the immediate area where the source was dispersed (Musolino and Harper, 2006).

Evacuation determination is another function where the availability of plume visualization within the first 1 hour would offer a significant benefit for decision makers. While it is true that absolute dose estimates may require significant source characterization, notional plume tracks initially based on conservative source term assumptions in combination with actual local weather conditions and urban terrain influences can offer a visual context for prioritizing regions and routes to efficiently relocate the citizenry. Such visuals may be produced by NARAC or other state/local prompt modeling efforts.

\section{Delayed Deliberate Evacuation}

Once the plume has passed, responders have life-saving priorities adequately managed, and personnel are available to prioritize evacuation of sheltered populations, orderly evacuations should begin. Through the use of survey equipment, responders or radiation-control experts who have arrived on-scene can determine routes of evacuation to eliminate or minimize the extent of exposure to contamination. Buildings should be evacuated through the path of least contamination as other threat/hazardous conditions permit. If the ground outside of a building is significantly/contaminated, mitigation efforts such as placing tarps over contaminated areas that people could walk over could provide protection to evacuees and minimize the decontamination efforts responders need to account for before releasing individuals.

\section{Evacuation Route Considerations}

Ideally, evacuation route planning will entail the identification of routes and times to expeditiously transport exposed or at-risk populations to uncontaminated/safe areas. A principal constraint on identifying a suitable route and time is selecting an evacuation corridor that is capable of handling a large flux of vehicles or foot traffic that is not already jammed or else damaged somehow during the attack. However, for an RDD event, additional constraints must also be considered: (1) the need to minimize cross-contamination to sensitive areas or structures, (2) the need to minimize exposure of evacuees to groundshine and/or re-suspended radioactive particulates, and (3) the possibility of secondary events/attacks, possibly targeting likely evacuation routes. These concerns will need to be balanced against risks of sheltering in place (e.g., building collapse, fires, groundshine).

Efficient evacuation of more than a few hundred individuals is a significant organizational challenge. Planning efforts are complicated by the need to have a single flexible plan that can be exercised against multiple threat scenarios. In general, if evacuation zones are required for an RDD, they may be smaller than those envisioned for other types of CBRNE disasters, if they do not 
include an element of contagious transfer that requires quarantine, and if they do not require immediate mobility of the public to avoid life- threatening exposure.

A communication package should be prepared that can be shared and understood by all affected individuals. This should include basic information about the radiation hazard, why they are being relocated, and a perceptive measure of urgency ranging from "immediate" to "with due care." This recommendation is intended to improve cooperation and effectiveness of the relocation by providing enough information so that individuals can judge the evacuation to be in their best interest. Information can be transmitted through many different media, including printed, recorded, broadcast, and spoken statements. The communication strategy should not underestimate the efficiency of word-of-mouth information spread, especially among large groups of people in similar stressful circumstances. Below is an example of a MARRP scripted message

\section{DRAFT Public Information Statement No. 3}

This message can be delivered some hours later.

There has been an explosion at (site of explosion). Fire, police, and health department personnel are on the scene. This was an explosive device where radioactive material was added to the explosives. This was NOT a nuclear bomb. The public should stay away to facilitate response efforts, and to reduce the possibility of radiation exposure from this incident.

Over the last hour we have determined that some radioactive material was carried (north, south, west, east) of the explosion site by the wind. At this point, we don't know the extent to which the winds have carried the radioactive material, so we continue to advise the public to stay indoors for their personal safety. As a precaution, if you are located within 5 miles east of (explosion site), you should close the doors and windows and turn off fans that bring in air from the outside. In-room fans that only recirculate air are OK to use. Air conditioning systems do not bring in air from the outside, and may be operated. If you were at (explosion site) when there was an explosion but have left and are not yet home, you may either continue home and shower there, or go to (evacuation location(s)).

Standard evacuation routes should be modified only to minimize exposure to radiation and the spread of contamination. Ideally, evacuation route planning will entail the identification of routes and times to expeditiously transport exposed or at-risk populations to uncontaminated/safe areas.

Outdoors, the significant radiological dose concern after passage of the particulate plume (i.e., before any likely RDD-event awareness) will be groundshine. Clearly, evacuation plans must take into account the need to minimize the stay time of both members of the public and first responders.

\section{Hazard Assessment and Control}

Evacuation/sheltering planning must first take into account the general nature of the threat and how it has been characterized as this will directly impact the course and timeliness of decisionmaking. 
Prompt monitoring performed by initial responders will include dose rate surveys, surface contamination surveys and large area wipes to determine immediate safety control zones and extent of radiological impact. Follow-up monitoring including more detailed radiation and contamination surveys, airborne monitoring for radiological and chemical contaminants, etc., will be performed by agencies such as public health departments.

It is important that expert assistance be enlisted as soon as safely possible to conduct air sampling. Exposure to re-suspended material from the point of origin and from surfaces along the plume track is the primary long-term hazard that might be avoided by evacuation. Early deployment of air sampling may help to confirm the priorities established for evacuation zones and it will provide a documented record of ambient air conditions for post recovery liability actions. Without a record of aerosol levels, all citizens throughout the region have an equal claim to treatment and recompense commensurate with worst-case exposure.

\section{Control Zone Boundaries}

In order to control the scene the first few hours following the detonation of an RDD, responders must define their radiation boundaries or decision points. These radiation decision points are demarcations of various radiation levels, which will be helpful in defining the types of activities and the time limitation that responders and members of the public can stay in order to limit their radiation exposure. Control Zones also aid in the prioritization of area activities. The location and exposure rates of the radiation decision points will depend on the physical size of the impacted area, presence of structures/landform features, and the existence of other hazards.

The information below is from Table 3 of the Los Angeles Multi-Agency Radiological Response Plan (MARRP). It defines import control zones used in that region and should be considered for broader California Planning. 


\begin{tabular}{|c|c|c|c|c|}
\hline Incident Zone & $\begin{array}{c}\text { Radiation } \\
\text { Type }\end{array}$ & \multicolumn{2}{|c|}{ Dose Rate / Contamination Level ${ }^{1}$} & Activities $^{2}$ \\
\hline $\begin{array}{l}\text { Support Zone } \\
\text { (SZ) }\end{array}$ & All & \multicolumn{2}{|c|}{ Below Contamination Reduction Zone levels } & $\begin{array}{l}\text { Staging, Incident } \\
\text { Command, etc. }\end{array}$ \\
\hline \multirow{3}{*}{$\begin{array}{l}\text { Contamination } \\
\text { Reduction Zone } \\
\text { (CRZ) }\end{array}$} & Gamma & \multicolumn{2}{|c|}{1 to $10 \mathrm{mR} / \mathrm{hr}^{3}$} & \multirow{3}{*}{$\begin{array}{l}\text { Decontamination } \\
\text { Activities }\end{array}$} \\
\hline & Beta & 1,000 to 10 & $00 \mathrm{cpm}^{4}$ & \\
\hline & Alpha & 100 to & $000 \mathrm{cpm}^{5}$ & \\
\hline \multirow{3}{*}{$\begin{array}{l}\text { Exclusion Zone } \\
\text { (EZ) }\end{array}$} & Gamma & \multicolumn{2}{|c|}{$10 \mathrm{mR} / \mathrm{hr}$ to $10 \mathrm{R} / \mathrm{hr}^{3}$} & \multirow{3}{*}{$\begin{array}{l}\text { Rescue, Evaluation, } \\
\text { Mitigation, and Activities }\end{array}$} \\
\hline & Beta & Above $100,000 \mathrm{cpm}^{4}$ & Respiratory protection & \\
\hline & Alpha & Above $10,000 \mathrm{cpm}^{5}$ & advised/required $^{8}$ & \\
\hline \multirow{3}{*}{$\begin{array}{c}\text { Extreme } \\
\text { Caution Area }\end{array}$} & Gamma & $\begin{array}{c}\text { Above } 10 \mathrm{R} / \mathrm{hr}^{3} \\
(200 \mathrm{R} / \mathrm{hr} \text { Turn Back } \\
\text { Limit) }\end{array}$ & \multirow{3}{*}{$\begin{array}{l}\text { Level B (SCBA) } \\
\text { respiratory protection } \\
\text { required }\end{array}$} & \multirow{3}{*}{$\begin{array}{l}\text { Rescue, Preplanned } \\
\text { Evaluation, and } \\
\text { Mitigation Activities }\end{array}$} \\
\hline & Beta & \multirow{2}{*}{ No Limits } & & \\
\hline & Alpha & & & \\
\hline
\end{tabular}

1 Incident Zone classification is based on all Radiation Types; i.e., if gamma dose rate is $1 \mathrm{mR} / \mathrm{hr}$, beta contamination level is $500 \mathrm{cpm}$, and alpha contamination level is $15,000 \mathrm{cpm}$, the proper Incident Zone classification is "Exclusion Zone" based on the alpha contamination.

2 All activities should be conducted in an area with the lowest levels of exposure and contamination as practicable to accomplish the mission.

3 Gamma radiation measured at approximately 3 feet with ion chamber, energy compensating Geiger-Mueller, or if necessary, sodium iodide or Pancake Geiger-Mueller (PGM). For PGM, use the backside down, with protective cap on PGM, and $\mathrm{mR} / \mathrm{hr}$ scale or $3,000 \mathrm{cpm}=1 \mathrm{mR} / \mathrm{hr}$. While values are reasonably good for most gamma emitters, consult a Radiation Technical Specialist if a gamma emitter other than cesium-137 is identified.

4 Beta radiation measured at approximately 1 inch from surface with a Pancake Geiger-Mueller (PGM) detector or a beta-specific detector. Caution: PGMs will respond to gamma radiation at approximately $3,000 \mathrm{cpm}$ per $1 \mathrm{mR} / \mathrm{hr}$ (for cesium-137). Therefore, when using a PGM to measure beta contamination levels, this gamma radiation response needs to be subtracted from the PGM readout before determining adherence to the beta levels in the table above. For example, if you have measured $1 \mathrm{mR} / \mathrm{hr}$ with a gamma detector (as noted in footnote 3 directly above), and using the PGM you measure $4,000 \mathrm{cpm}$, you need to subtract $3,000 \mathrm{cpm}$ to account for the gamma response before determining the beta contamination level for use with the table above.

5 Alpha radiation measured at approximately $1 / 2$ inch from a relatively smooth surface (such as a concrete sidewalk) with an alpha-specific detector. If an alpha-specific detector is not available, a PGM may be used as noted in Standard Operating Guide No. 2, How to Distinguish Between Alpha, Beta, and Gamma Radiation Using a Pancake Geiger-Mueller Survey Meter. Caution: Alpha radiation is very difficult to measure accurately. Presence of moisture, oil, dust, or dirt may shield all alpha. Seek Radiation Technical Specialist assistance if alpha contamination is detected.

6 Decontamination activities should occur in areas with contamination levels no greater than $10 \%$ of the contamination release criteria (refer to Tables $10,11,12$, or 13) to allow reasonable speed surveys.

7 Residents and other non-essential personnel already within the Contamination Reduction Zone may be allowed to shelter-in-place instead of evacuate, pending logistics for their removal.

8 Respiratory protection should be worn for entry into the exclusion zone and must be worn in areas above $1 \mathrm{R} / \mathrm{hr}$ for gamma, 100,000 cpm for beta, and 10,000 cpm for alpha.

9 Residents and other non-essential personnel within the Exclusion Zone need to be evacuated. Shelter-in-place should occur until evacuation is feasible.

10 Consult Incident Commander or Radiation Technical Specialist to exceed limit.

cpm counts per minute

$\mathrm{mR} / \mathrm{hr}$ milliroentgen per hour

$\mathrm{R} / \mathrm{hr} \quad$ roentgen per hour

SCBA self-contained breathing apparatus

References: CRCPD 2006, NCRP 2005, and NCRP 2001 (see Volume II for specific citation) 


\section{References}

(2010). Responding to a Radiological or Nuclear Terrorism Incident - A Guide for Decision Makers: (Report No. 165). National Council on Radiation Protection and Measurements. (NCRP).

(2006). Handbook for Responding to a Radiological Dispersal Device: First Responder's Guide-the First 12 Hours. Conference of Radiation Control Program Directors, Inc. (CRCPD).

Radiological Dispersion Device (RDD). Ready. http://www.ready.gov/radiological-dispersiondevice-rdd

(MARRP) Los Angeles County, Department of Public Health, Radiation Management; Los Angeles County Multi-Agency Radiological Response Plan. February 2009. For more information contact (213) 351-7897

Musolino SV, Harper FT. (2006) Emergency Response Guidance for the First 48 Hours after the Outdoor Detonation of an Explosive Radiological Device. Health Physics 2006 Apr;90(4):377-85.

(Musolino, 2013) Musolino SV, Harper FT. Brooke Buddemeier, BR. Brown, M. Schlueck, R (2013) Updated Emergency Response Guidance for the First $48 \mathrm{H}$ After the Outdoor Detonation of an Explosive Radiological Dispersal Device. Health Physics 2013 July ; 65-73

(2005). FREQUENTLY ASKED QUESTIONS (FAQS): Dirty Bombs. Center for Disease Control and Prevention: Emergency Preparedness and Response.

http://emergency.cdc.gov/radiation/pdf/dirtybombs.pdf

(FR 73-149) Department of Homeland Security (August 2008). "Protective Action Guides for Radiological Dispersion Device (RDD) and Improvised Nuclear Device (IND) Incidents,” Federal Register 73, No. 149. 


\section{Appendix 1. RDD Response Summary Flow Chart}

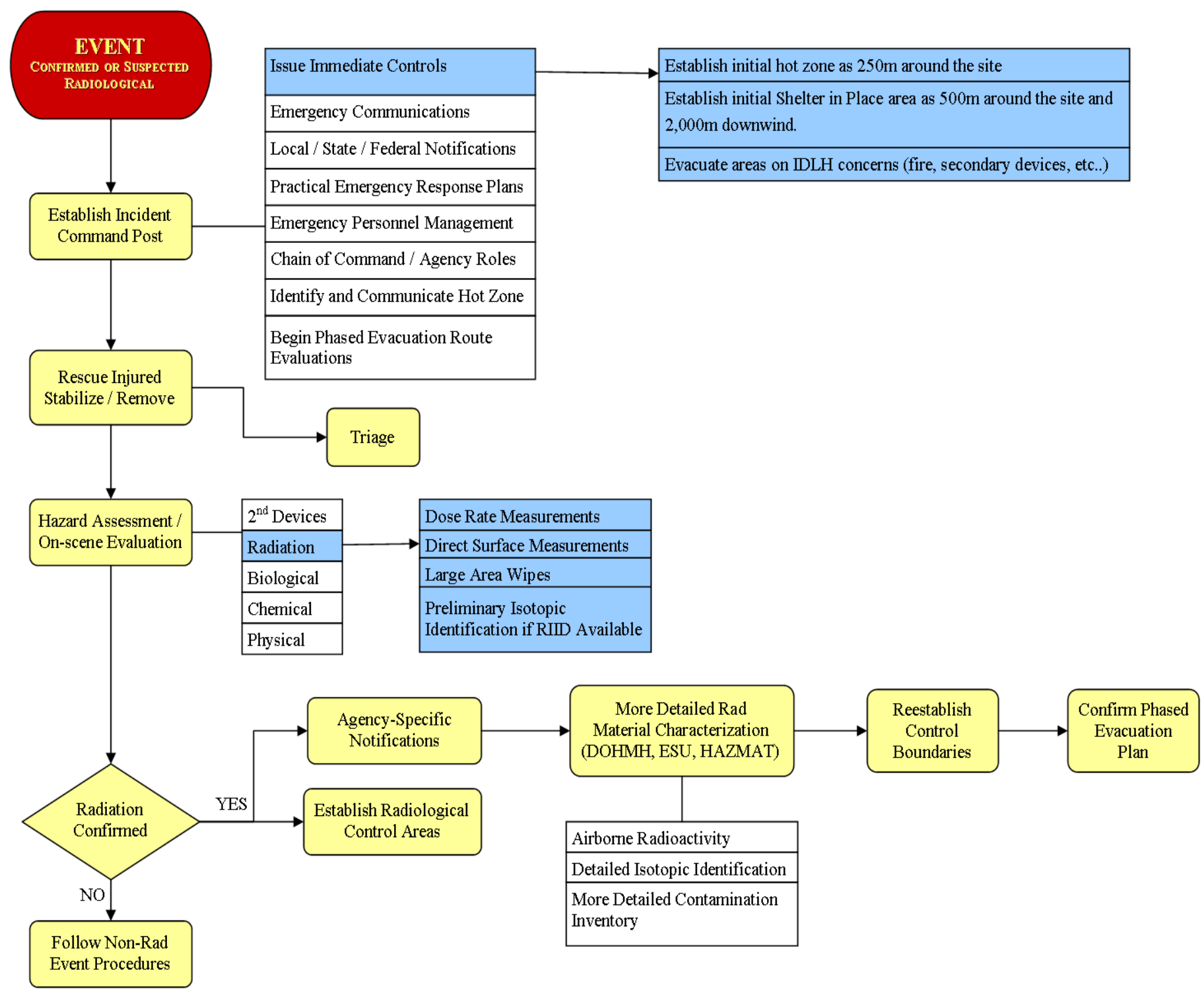

\section{Additional flow chart options...}




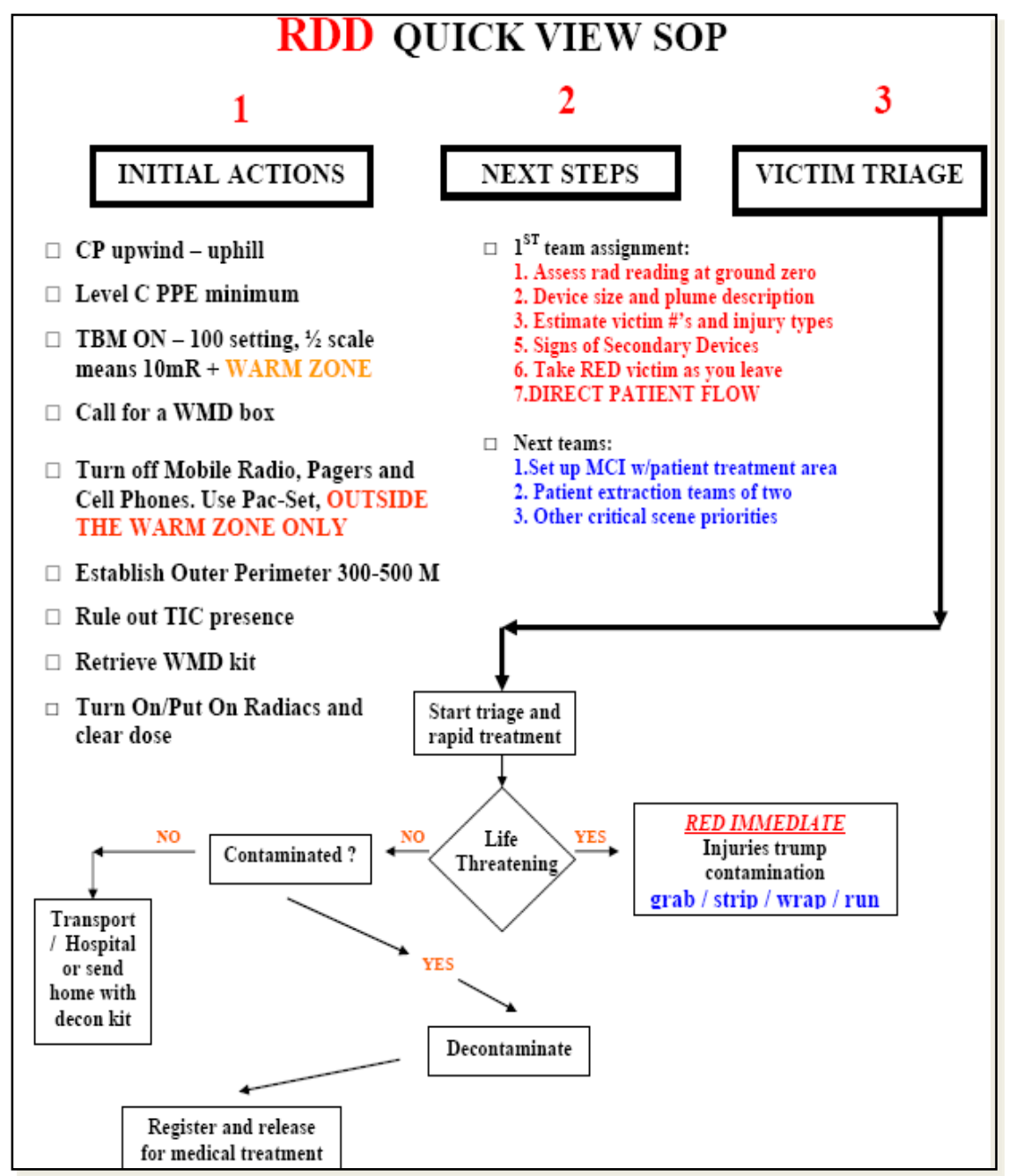




\section{Appendix 2. Building Ventilation Systems}

It should be noted that there is no universal agreement on the subject of ventilation shut-off in buildings. This is because protection from airborne particulates is a complex issue to consider and engineers and modelers are reporting variable recommendations on this subject. The protection offered by building materials from groundshine stemming from deposited particulates on the exterior of the building is a straightforward issue; however, protection from airborne particulates is a more complex consideration. Some considerations:

- Regardless of whether the ventilation is on or off, being inside a building is always more

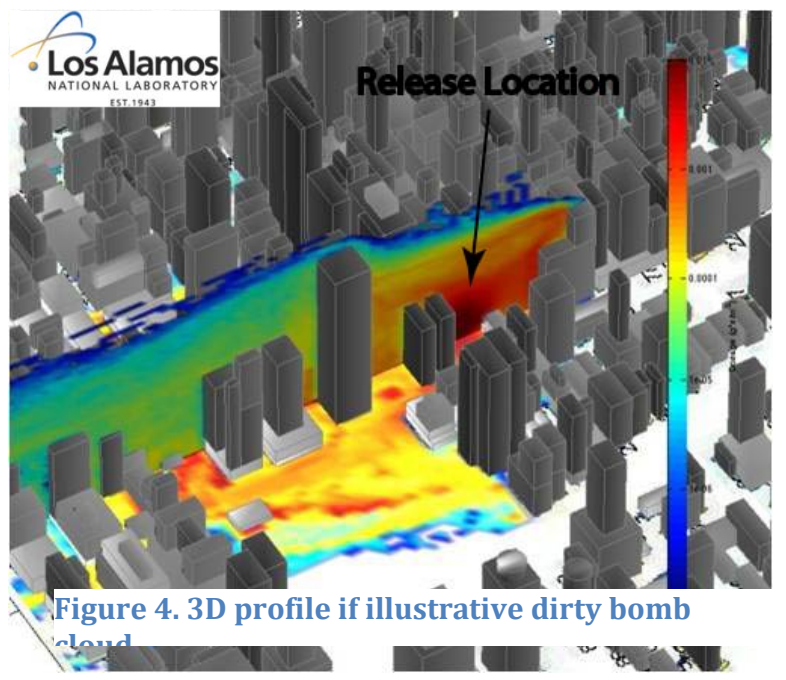
protective than being outside at the same location for the same amount of time.

- If the contamination has yet to reach the building, efforts to reduce the infiltration of particles from the outside will reduce exposure to building occupants.

- For some buildings and for some time periods, turning off ventilation may increase indoor exposures. However, the action is still generally recommended as protective to the majority.

- In times of severe cold or heat, the risk of temperature exposure is likely to be of higher risk than the radiological exposure.

- In a high-rise building the uppermost floors might have little or no airborne radioactivity, radioactive contamination, or radiation dose rate; even if lower floors require evacuation.

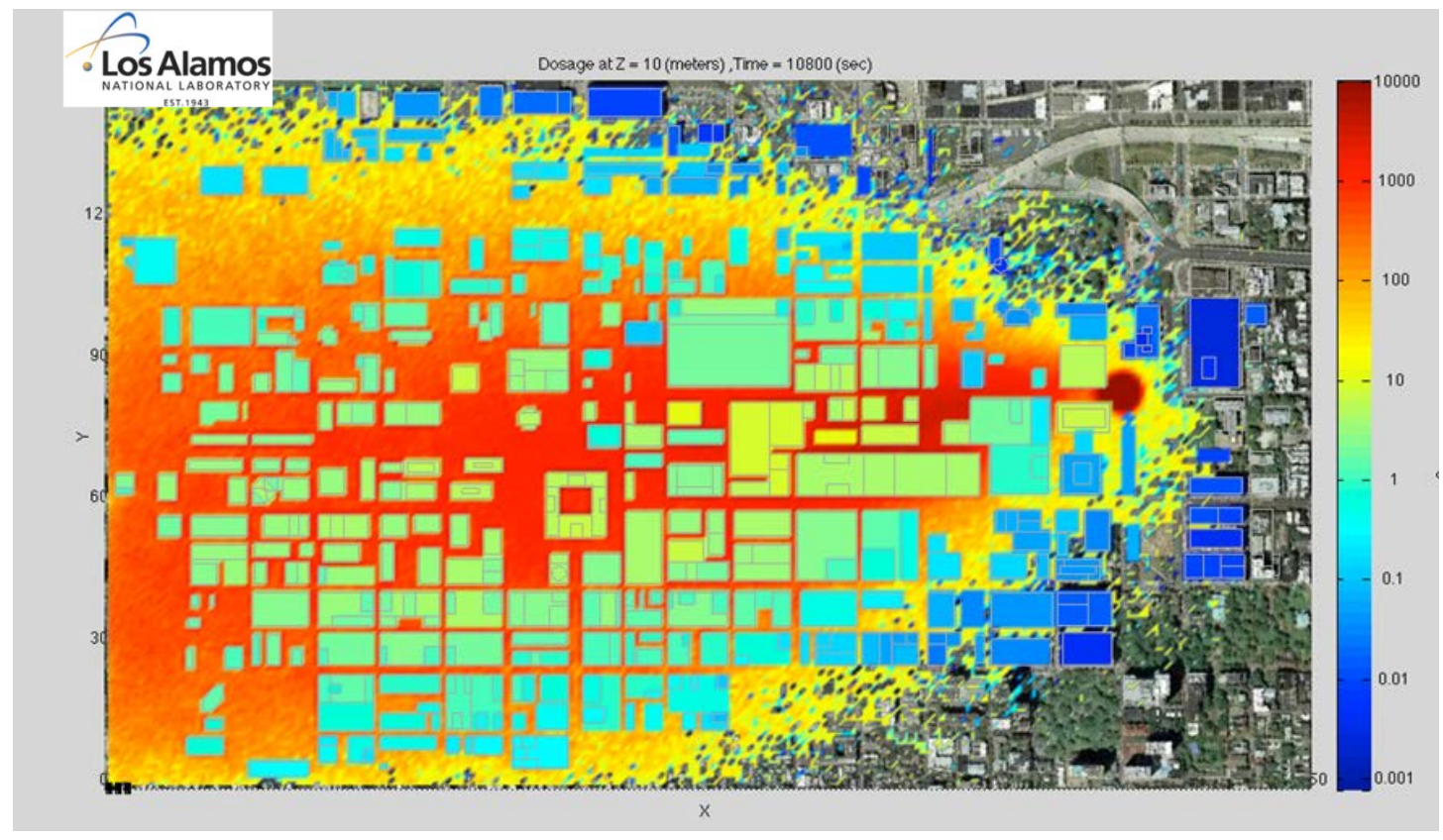

Figure 5. Interior and exterior exposures after an outdoor dirty bomb 
Recommendation: For RDD response planning, the shelter in place order should be accompanied with instructions on how to reduce particulate infiltration such as closing windows and doors and reducing outside air ventilation systems. Ventilation system shut down is especially valuable in areas that the contaminated smoke has not reached and when temperature extremes would not pose a hazard to building occupants. If a building specific analysis of appropriate actions has been performed, then those actions should be implemented on a case by case basis.

Below is some of the (conflicting) information and recommendations. Assuming an explosive release, in the first few minutes following the RDD event, peak indoor radioactive particulate concentrations (reflecting particulates drawn into the building through the HVAC system) will remain far below peak concentrations from the passing outdoor plume. However, at this very early stage, it is unlikely that there would be any awareness of the radiological nature of the plume, so the indoor protective factor is simply a given (i.e., it will not actively be considered in any response decision-making). Nevertheless, during subsequent minutes, airborne particulate concentrations remain within the building interiors owing to a lack of prevailing airflow to flush particulates away (as in the case of the outdoor plume) so that the time-integrated indoor inhalation becomes a comparatively more significant issue, particularly for older buildings with inefficient HVAC filters for very small particulates at the low end of the respirable particle size range. Ironically, the operation of the HVAC system will contribute substantially to the removal of particulates over time onto the filter, regardless of efficiency.

Some existing guidance recommends shut-down of HVAC systems following a suspected CBR attack. For example, the security advice web page for MI5 states:

"In the event of a suspected CBR incident, switch off all air-conditioning, ventilation and other systems or items (e.g. fans and personal computers) that may contribute to air movement. Any air movement can aid the spread of contamination. Ensure your planning includes how to implement rapid shut-down of building HVAC systems, and that it is known how these systems can be restarted following the all-clear from the emergency services.” (http://www.mi5.gov.uk/output/Page264.html).

It is not clear whether such a recommendation is universally the most appropriate course of action, particularly in urban areas with modern buildings and high efficiency HVAC filters, although urban canyon settings with possible stagnation zones contributes additional complexity to this analysis. In less densely developed areas, including areas characterized primarily by houses and apartments with window air units, the decision as to whether or not to operate central heating and cooling systems during a shelter-in-place response would need to take into account the time scale of the outdoor plume passage, filtration efficiency, and leakage of air into or out of the building.

Calculations comparing time-integrated indoor and outdoor inhalation and groundshine doses, based upon a Gaussian plume model for the outdoor plume coupled with a mixed tank model for associated indoor effects of an RDD for various general building types have been performed [Ref X]. These simple screening model calculations suggest that buildings offer substantial sheltering from 
outdoor airborne particulates, although this effect depends strongly on particulate size and the HVAC filter efficiency. The model results also suggest that HVAC filtration may be an important means for removing particulates from indoor air and thus it may not always be advisable to shut off an HVAC system following an RDD event. These calculations suggest that in most post-event situations, building HVAC systems should not be turned off, as the particulate cloud will likely have long since passed the building by the time the radiological threat has been identified. Rather, the HVAC system may serve to remove particulates from the air inside the building faster than would occur solely by settling, hence reducing the time-integrated inhalation dose to the victims.

Given this variability, specific recommendations should be based on the type of building and HVAC system. 


\section{Appendix 3. Shelter/Evacuation and Control Zone Recommendation Reference Summary}

\begin{tabular}{|c|c|c|c|}
\hline Agency & Evacuation & Shelter & Comments \\
\hline $\begin{array}{l}\text { IAEA Manual for } \\
\text { First Responders to } \\
\text { a Radiological } \\
\text { Emergency }\end{array}$ & $\begin{array}{l}\text { Assume that } \\
\text { people from the } \\
\text { area are } \\
\text { contaminated. }\end{array}$ & See comment. & $\begin{array}{l}\text { For those members of the public who } \\
\text { are within the inner cordoned area } \\
\text { (defined as greater than } 10 \mathrm{mR} / \mathrm{h} \text { ) } \\
\text { when first responders arrive: } \\
\text { (1) Promptly evacuate as possible. } \\
\text { Before evacuation takes place instruct } \\
\text { the public to take best available } \\
\text { shelter (e.g. go to indoor hall, stay } \\
\text { away from windows). }\end{array}$ \\
\hline $\begin{array}{l}\text { IAEA (2003) } \\
\text { Method for } \\
\text { Developing } \\
\text { Arrangements for } \\
\text { Response to a } \\
\text { Nuclear or } \\
\text { Radiological } \\
\text { Emergency }\end{array}$ & $\begin{array}{l}\text { Intervention } \\
\text { level at } 10 \mathrm{mSv} \\
(1 \mathrm{rem}): \text { Shelter }\end{array}$ & $\begin{array}{l}\text { Intervention } \\
\text { level at } 50 \mathrm{mSv} \\
(5 \mathrm{rem}): \\
\text { Evacuation }\end{array}$ & $\begin{array}{l}\text { Sheltering is not recommended for } \\
\text { longer than two days. Authorities may } \\
\text { wish to recommend sheltering at } \\
\text { lower intervention levels for shorter } \\
\text { periods or so as to facilitate further } \\
\text { protective actions, e.g. evacuation. }\end{array}$ \\
\hline $\begin{array}{l}\text { CRCPD RDD } \\
\text { Handbook (2006) }\end{array}$ & $\begin{array}{l}\text { In the absence of } \\
\text { any other } \\
\text { information, } \\
\text { evacuate to } 1650 \\
\mathrm{ft}(500 \mathrm{~m}) \text { from } \\
\text { the detonation } \\
\text { site in all } \\
\text { directions. }\end{array}$ & $\begin{array}{l}\text { Shelter if in } \\
\text { immediate } \\
\text { area. }\end{array}$ & $\begin{array}{l}\text { Keep as great a distance as possible } \\
\text { from these radiation sources/areas. } \\
\text { The public in the immediate areas } \\
\text { should seek shelter indoors rather } \\
\text { than stay outside. }\end{array}$ \\
\hline NCRP 138 & See comment & See comment & $\begin{array}{l}\text { Table } 8.2 \text { a provides "Countermeasures } \\
\text { available for each route of exposure } \\
\text { listed in Table } 8.1 \text { ". } \\
\text { Table } 8.2 \text { b provides corresponding } \\
\text { "Countermeasures available for each } \\
\text { phase of an event" that provides time } \\
\text { phased actions that include evacuation } \\
\text { and sheltering. }\end{array}$ \\
\hline
\end{tabular}


RDD Shelter/Evacuation Technical Basis

\begin{tabular}{|l|l|l|l|}
\hline NCRP 165 & See comment & See comment & $\begin{array}{l}\text { NCRP recommends that the initial } \\
\text { public protective action for both } \\
\text { radionuclide dispersion incidents and } \\
\text { nuclear detonations be early, adequate } \\
\text { sheltering followed by delayed, } \\
\text { informed evacuation. Until the level } \\
\text { and extent of contamination can be } \\
\text { determined, efforts should be made to } \\
\text { avoid being outdoors in potentially- } \\
\text { contaminated areas. }\end{array}$ \\
\hline $\begin{array}{l}\text { FEMA 358, 05/10 } \\
\text { Radioactive }\end{array}$ & $\begin{array}{l}\text { Evacuate } \\
\text { personnel who } \\
\text { were in the } \\
\text { immediate } \\
\text { downwind area. }\end{array}$ & NONE \\
$\begin{array}{l}\text { Transportation And } \\
\text { Incident Response }\end{array}$ & & NONE \\
(the Q\&A booklet) & & & \\
\hline
\end{tabular}


RDD Shelter/Evacuation Technical Basis

\section{Appendix 4: Additional Shelter/Evacuation References}

Immediate Public Sheltering Recommendations are summarized below. [from FEMA's webside "Are You Ready? Radiological Dispersion Device"

(http://www.fema.gov/areyouready/radiological_dispersion_device.shtm)]:

The Centers for Disease Control (CDC) has also prepared recommendations for sheltering and evacuation (“Emergency Preparedness \& Response, FAQs about Dirty Bombs," located at http://www.bt.cdc.gov/radiation/dirtybombs.asp), summarized below. The CDC catalogued simple steps recommended by doctors and radiation experts. The actions taken depend individual location when the incident occurs: outside, inside, or in a vehicle.

Table 1. FEMA Sheltering Recommendations

\begin{tabular}{|l|r|}
\hline Outdoors & Indoors \\
\hline $\begin{array}{l}\text { Seek immediate shelter indoors in } \\
\text { the nearest undamaged building. }\end{array}$ & $\begin{array}{l}\text { Seek shelter immediately, preferably } \\
\text { underground or in an interior room of a } \\
\text { building, placing as much distance and dense } \\
\text { shielding as possible between you and the } \\
\text { outdoors where the radioactive material may } \\
\text { be }\end{array}$ \\
\hline $\begin{array}{l}\text { If appropriate shelter is not } \\
\text { available, move as rapidly as is safe } \\
\text { upwind and away from the } \\
\text { location of the explosive blast. } \\
\text { Then, seek appropriate shelter as } \\
\text { soon as possible. }\end{array}$ & $\begin{array}{l}\text { Retrieve your disaster supplies kit and a } \\
\text { battery-powered radio, and take them to your } \\
\text { shelter room. }\end{array}$ \\
\hline $\begin{array}{l}\text { Listen for official instructions and } \\
\text { follow directions. }\end{array}$ & $\begin{array}{l}\text { If you have time, turn off ventilation and } \\
\text { heating systems, close windows, vents, } \\
\text { fireplace dampers, exhaust fans, and clothes } \\
\text { dryer vents. }\end{array}$ \\
\hline & $\begin{array}{l}\text { Seal windows and external doors that do not } \\
\text { fit snugly with duct tape to reduce infiltration } \\
\text { of radioactive particles. Plastic sheeting will } \\
\text { not provide shielding from radioactivity nor } \\
\text { from blast effects of a nearby explosion. }\end{array}$ \\
\hline & $\begin{array}{l}\text { Listen for official instructions and follow } \\
\text { directions. }\end{array}$ \\
\hline
\end{tabular}


RDD Shelter/Evacuation Technical Basis

Table 2. CDC Sheltering Recommendations

If you are outside and close to the incident:

- Cover your nose and mouth with a cloth to reduce the risk of breathing in radioactive dust or smoke.

- Don't touch objects thrown off by an explosion.-They might be radioactive.

- Quickly go into a building where the walls and windows have not been broken. This area will shield you from radiation that might be outside.

- Once you are inside, take off your outer layer of clothing and seal it in a plastic bag if available. Put the cloth you used to cover your mouth in the bag too. Removing outer clothes may get rid of up to $90 \%$ of radioactive dust. Put the plastic bag where others will not touch it and keep it until authorities tell you what to do with it.

- Shower or wash with soap and water. Be sure to wash your hair. Washing will remove any remaining dust.

- Tune to the local radio or television news for more instructions.

If you are inside and close to the incident:

- If the walls and windows of the building are not broken, stay in the building and do not leave.

- To keep radioactive dust or powder from getting inside, shut all windows, outside doors, and fireplace dampers. Turn off fans and heating and air-conditioning systems that bring in air from the outside. It is not necessary to put duct tape or plastic around doors or windows.

- If the walls and windows of the building are broken, go to an interior room and do not leave. If the building has been heavily damaged, quickly go into a building where the walls and windows have not been broken. If you must go outside, be sure to cover your nose and mouth with a cloth.

- Once you are inside, take off your outer layer of clothing and seal it in a plastic bag if available. Store the bag where others will not touch it.

- Shower or wash with soap and water, removing any remaining dust. Be sure to

- wash your hair.

- Tune to local radio or television news for more instructions. If you are in a car when the incident happens:

- Close the windows and turn off the air conditioner, heater, and vents.

- Cover your nose and mouth with a cloth to avoid breathing radioactive dust or smoke.

- If you are close to your home, office, or a public building, go there immediately and go inside quickly.

- If you cannot get to your home or another building safely, pull over to the side of the road and stop in the safest place possible. If it is a hot or sunny day, try to stop under a bridge or in a shady spot.

- Turn off the engine and listen to the radio for instructions.

- Stay in the car until you are told it is safe to get back on the road.

The American Red Cross and CDC offer and Excellent Shelter in Place factsheet available at http://www.redcross.org/preparedness/cdc english/Sheltering.asp; excerpts below:

What Shelter-in-Place Means: 
One of the instructions you may be given in an emergency where hazardous materials may have been released into the atmosphere is to shelter-in-place. This is a precaution aimed to keep you safe while remaining indoors. (This is not the same thing as going to a shelter in case of a storm.) Shelter-in-place means selecting a small, interior room, with no or few windows, and taking refuge there. It does not mean sealing off your entire home or office building. If you are told to shelter-in-place, follow the instructions provided in this Fact Sheet.

Why You Might Need to Shelter-in-Place: Chemical, biological, or radiological contaminants may be released accidentally or intentionally into the environment. Should this occur, information will be provided by local authorities on television and radio stations on how to protect you and your family. Because information will most likely be provided on television and radio, it is important to keep a TV or radio on, even during the workday. The important thing is for you to follow instructions of local authorities and know what to do if they advise you to shelter-in-place.

\section{How to Shelter-in-Place}

\section{At Home:}

- Close and lock all windows and exterior doors.

- If you are told there is danger of explosion, close the window shades, blinds, or curtains.

- Turn off all fans, heating and air conditioning systems.

- Close the fireplace damper.

- Get your family disaster supplies kit and make sure the radio is working.

- Go to an interior room without windows that's above ground level. In the case of a chemical threat, an above-ground location is preferable because some chemicals are heavier than air, and may seep into basements even if the windows are closed.

- Bring your pets with you, and be sure to bring additional food and water supplies for them.

- It is ideal to have a hard-wired telephone in the room you select. Call your emergency contact and have the phone available if you need to report a life-threatening condition. Cellular telephone equipment may be overwhelmed or damaged during an emergency.

- Use duct tape and plastic sheeting (heavier than food wrap) to seal all cracks around the door and any vents into the room.

- Keep listening to your radio or television until you are told all is safe or you are told to evacuate. Local officials may call for evacuation in specific areas at greatest risk in your community.

\section{At Work:}

- $\quad$ Close the business.

- Bring everyone into the room(s). Shut and lock the door(s).

- If there are customers, clients, or visitors in the building, provide for their safety by asking them to stay - not leave. When authorities provide directions to shelter-in-place, they want everyone to take those steps now, where they are, and not drive or walk outdoors. 
- Unless there is an imminent threat, ask employees, customers, clients, and visitors to call their emergency contact to let them know where they are and that they are safe.

- Turn on call-forwarding or alternative telephone answering systems or services. If the business has voice mail or an automated attendant, change the recording to indicate that the business is closed, and that staff and visitors are remaining in the building until authorities advise it is safe to leave.

- Close and lock all windows, exterior doors, and any other openings to the outside.

- If you are told there is danger of explosion, close the window shades, blinds, or curtains.

- Have employees familiar with your building's mechanical systems turn off all fans, heating and air conditioning systems. Some systems automatically provide for exchange of inside air with outside air - these systems, in particular, need to be turned off, sealed, or disabled.

- Gather essential disaster supplies, such as nonperishable food, bottled water, batterypowered radios, first aid supplies, flashlights, batteries, duct tape, plastic sheeting, and plastic garbage bags.

- Select interior room(s) above the ground floor, with the fewest windows or vents. The room(s) should have adequate space for everyone to be able to sit in. Avoid overcrowding by selecting several rooms if necessary. Large storage closets, utility rooms, pantries, copy and conference rooms without exterior windows will work well. Avoid selecting a room with mechanical equipment like ventilation blowers or pipes, because this equipment may not be able to be sealed from the outdoors.

- It is ideal to have a hard-wired telephone in the room(s) you select. Call emergency contacts and have the phone available if you need to report a life-threatening condition. Cellular telephone equipment may be overwhelmed or damaged during an emergency.

- Use duct tape and plastic sheeting (heavier than food wrap) to seal all cracks around the door(s) and any vents into the room.

- Write down the names of everyone in the room, and call your business' designated emergency contact to report who is in the room with you, and their affiliation with your business (employee, visitor, client, customer.)

- Keep listening to the radio or television until you are told all is safe or you are told to evacuate. Local officials may call for evacuation in specific areas at greatest risk in your community.

\section{At School:}

- Close the school. Activate the school's emergency plan. Follow reverse evacuation procedures to bring students, faculty, and staff indoors.

- If there are visitors in the building, provide for their safety by asking them to stay - not leave. When authorities provide directions to shelter-in-place, they want everyone to take those steps now, where they are, and not drive or walk outdoors.

- Provide for answering telephone inquiries from concerned parents by having at least one telephone with the school's listed telephone number available in the room selected to provide shelter for the school secretary, or person designated to answer these calls. This room should also be sealed. There should be a way to communicate among all rooms where people are sheltering-in-place in the school. 
- Ideally, provide for a way to make announcements over the school-wide public address system from the room where the top school official takes shelter.

- If children have cell phones, allow them to use them to call a parent or guardian to let them know that they have been asked to remain in school until further notice, and that they are safe.

- If the school has voice mail or an automated attendant, change the recording to indicate that the school is closed, students and staff are remaining in the building until authorities advise that it is safe to leave.

- Provide directions to close and lock all windows, exterior doors, and any other openings to the outside.

- If you are told there is danger of explosion, direct that window shades, blinds, or curtains be closed.

- Have employees familiar with your building's mechanical systems turn off all fans, heating and air conditioning systems. Some systems automatically provide for exchange of inside air with outside air - these systems, in particular, need to be turned off, sealed, or disabled.

- Gather essential disaster supplies, such as nonperishable food, bottled water, batterypowered radios, first aid supplies, flashlights, batteries, duct tape, plastic sheeting, and plastic garbage bags.

- Select interior room(s) above the ground floor, with the fewest windows or vents. The room(s) should have adequate space for everyone to be able to sit in. Avoid overcrowding by selecting several rooms if necessary. Classrooms may be used if there are no windows or the windows are sealed and can not be opened. Large storage closets, utility rooms, meeting rooms, and even a gymnasium without exterior windows will also work well.

- It is ideal to have a hard-wired telephone in the room(s) you select. Call emergency contacts and have the phone available if you need to report a life-threatening condition. Cellular telephone equipment may be overwhelmed or damaged during an emergency.

- Bring everyone into the room. Shut and lock the door.

- Use duct tape and plastic sheeting (heavier than food wrap) to seal all cracks around the door(s) and any vents into the room.

- Write down the names of everyone in the room, and call your schools' designated emergency contact to report who is in the room with you.

- Listen for an official announcement from school officials via the public address system, and stay where you are until you are told all is safe or you are told to evacuate. Local officials may call for evacuation in specific areas at greatest risk in your community.

\section{In Your Vehicle:}

If you are driving a vehicle and hear advice to "shelter-in-place" on the radio, take these steps:

- If you are very close to home, your office, or a public building, go there immediately and go inside. Follow the shelter-in-place recommendations for the place you pick described above.

- If you are unable to get to a home or building quickly and safely, then pull over to the side of the road. Stop your vehicle in the safest place possible. If it is sunny outside, it is preferable to stop under a bridge or in a shady spot, to avoid being overheated. 
- Turn off the engine. ? Close windows and vents.

- If possible, seal the heating/air conditioning vents with duct tape.

- Listen to the radio regularly for updated advice and instructions.

- Stay where you are until you are told it is safe to get back on the road. Be aware that some roads may be closed or traffic detoured. Follow the directions of law enforcement officials.

Local officials on the scene are the best source of information for your particular situation. Following their instructions during and after emergencies regarding sheltering, food, water, and clean up methods is your safest choice.

Remember that instructions to shelter-in-place are usually provided for durations of a few hours, not days or weeks. There is little danger that the room in which you are taking shelter will run out of oxygen and you will suffocate. 